\title{
A Process Evaluation of Toronto's First Youth Mental Health Court
}

Davis, Krista M., Peterson-Badali, Michele., Weagant, Brian., Skilling, Tracey.

\author{
Version Post-print/accepted manuscript \\ Citation Davis, K., Peterson-Badali, M., Weagant, B. \& Skilling, T. (2015). A \\ process evaluation of Toronto's first youth mental health court. \\ Canadian Journal of Criminology and Criminal Justice, 57(2)
}

DOI 10.3138/CJCCJ.2014.E10 


\title{
A Process Evaluation of Toronto's First Youth Mental Health Court
}

\author{
Krista M. Davis \\ York University, Department of Psychology \\ Michele Peterson-Badali \\ Ontario Institute for Studies in Education, University of Toronto \\ Brian Weagant \\ Ontario Court of Justice \\ Tracey A. Skilling \\ Centre for Addiction and Mental Health and the University of Toronto
}

Submitted March 27, 2014

We would like to thank the following people for their assistance with this study: Kaley Smith, Rebecca Hannah, Lynn Bushell, Michelle Sherwood, Scott Graham, Brian Smegal, Uppala Chandrasekera, Zohrah Haqanee, and Chris Baldock. This research was supported by funding from the Youth Justice and Strategic Initiatives Section of the Department of Justice Canada and from the Provincial Human Services and Justice Coordinating Committee.

Correspondence should be addressed to Michele Peterson Badali, Department of Applied Psychology and Human Development, Ontario Institute for Studies in Education, University of Toronto, 252 Bloor Street West, $9^{\text {th }}$ Floor, Toronto, Ontario, Canada, M5S 1V6, m.petersonbadali@utoronto.ca. 


\title{
A Process Evaluation of Toronto's First Youth Mental Health Court
}

\begin{abstract}
Youth mental health courts are a relatively new type of specialty court designed to address the mental health needs of justice-involved youth, usually with the ultimate goal of desistance from future offending. As part of a process evaluation of Toronto's first youth mental health court, court records and files for 127 youth who participated in the program from its inception in 2011 until August 2013 were reviewed to: 1) describe the operation of the court and the clients it serves, 2) explore predictors of successful court completion, and 3) examine how the court addresses the mental health and criminogenic needs of its clients. Most clients successfully completed the court requirements, with case processing time comparable to 'traditional' youth courts; completers were more likely than non-completers to have a mental health diagnosis and higher initial treatment motivation. Half of youth received treatment targeted to their identified mental health needs. Analysis of a subsample of cases indicated that for most youth, mental health issues were indirectly related to their offences, indicating the need to address criminogenic needs in addition to mental health needs in the court. Findings are discussed with regards to best practice for treating justice-involved youth with mental health needs.
\end{abstract}

Keywords: mental health court, youth, rehabilitation, evaluation, 


\section{Introduction}

Mental health courts were first introduced to Canada in 1998 to address the growing concern regarding the mental health needs of justice-involved populations, (Schneider Bloom and Hereema 2007; Slinger and Roesch 2010). Such programs seek to divert accused persons with mental illness out of the criminal justice system and into community treatment through a more collaborative and less adversarial process than in the traditional court system (Schneider et al. 2007; Steadman Redlich Callahan Robbins and Vesselinov 2011). Within the adult literature, mental health courts have been found to increase treatment service usage and are moderately effective in reducing recidivism (Boothroyd Poythress McGaha and Petrila 2003; Sarteschi Vaughn and Kim 2011). With their apparent success, these courts have recently been adapted for youth. The first Canadian mental health court for youth was opened in Ottawa in 2008 (PerkinsMcVey McCormick Leger Bretton and Motayne 2009); since then, several similar programs have been established across Ontario.

\section{Mental Health Court Research}

Despite their recent adaptation for youth, there is a dearth of research on youth mental health courts and little is known about their characteristics and operations. Callahan, Cocozza, Steadman, and Tillman (2012) conducted a national survey of juvenile mental health courts in the United States. They reported that programs were typically run by either the juvenile court, probation services, or a combination of both. The most common diagnoses amongst participants were Bipolar Disorder (27\%), followed by Depression (23\%), and Attention Deficit/Hyperactivity Disorder (16\%). A guilty plea was required in most courts and various incentives were used to promote participation (e.g., dismissal of charges, praise by the judge or probation officer, and gift cards). Multidisciplinary teams were also a common feature of the 
programs surveyed. Interestingly, many of the courts set minimum time period of participation with the most common being 6 to 9 months - but no maximum time limit. The authors highlighted that while mental health courts for youth share many similarities with adult programs, they face unique challenges with regards to diagnosis and treatment, as well as how to involve families and address school related issues.

Evidence is also emerging that participation in youth mental health courts results in reduced rates of reoffending (Behnken 2008; Heretick and Russell 2013). Taken together, these findings suggest that mental health courts may be a promising option for justice-involved youth with mental health needs but research documenting the operations of such courts is needed to better understand the mechanisms related to such outcomes.

\section{Mental Health, Offending, and Rehabilitation}

The primary goal of mental health courts it the rehabilitation of offenders. As such, mental health courts and mental health court research should consider existing empirical evidence relevant to rehabilitation. For example, research has identified strong and direct predictors of recidivism (termed 'criminogenic needs') that are essential to assess and address to reduce reoffending (Andrews and Bonta 2010; Andrews Bonta and Hoge 1990; Hollin and Palmer 2003; Schlager and Pacheco 2011; Simourd 2004). These variables are a critical component of the Risk Need Responsivity (RNR) framework, a theoretically-grounded and empirically-supported model based on three key principles: 1) that the most intensive treatment should be reserved for those at highest risk for recidivism and low risk individuals should not be 'overprogrammed' (Risk principle); 2) that treatment should address an offender's criminogenic needs (Need principle); and 3) that treatment should be tailored to individual characteristics (e.g., motivation, learning style) that - while not directly predictive of offending - impact the 


\section{TSpace Research Repository}

effectiveness of interventions that target criminogenic needs (Responsivity principle; Andrews et al. 1990).

While there is strong empirical evidence for treating criminogenic needs to reduce recidivism, less is known on how best to treat offenders with mental health needs. In the RNR framework, several identified criminogenic needs are also features of mental health diagnoses (e.g., impulsivity, anger and aggression, antisociality) but for the most part, mental health diagnoses, while associated with criminal behaviour, are not strong predictors of recidivism (McCormick Peterson-Badali and Skilling, 2014) ${ }^{1}$. Within the RNR framework, most mental health needs (e.g., symptoms of mood and/or anxiety disorders) are better conceptualized as responsivity factors that influence an individual's ability to successfully engage in the treatment of criminogenic needs (Bonta 1995). Indeed, research indicates that for a small proportion of individuals with mental health problems, there is a direct or causal relationship between mental illness and criminal behaviour but for a substantial majority of offenders with mental illness, the relationship between mental illness and criminal behaviour is indirect and mediated by criminogenic needs (Skeem Manchak and Peterson, 2011).

Understanding these different relationships has important implications for intervention. When mental health problems are directly related to an individual's offending, mental health intervention is an appropriate approach to achieve rehabilitation (i.e., reduce the likelihood and/or frequency of reoffending). However, where there is an indirect relationship between mental health and criminal behaviour, it is important that treatment consider both criminogenic and mental health needs when implementing interventions. This has clear implications for the functioning of mental health courts and associated research and, as such, the current study considers the results in relation to the empirical knowledge on offender rehabilitation. 


\section{The Current Study}

The current study is part of a larger process evaluation exploring the functioning of a youth mental health court in Toronto, Canada. It is a resolution court for young people charged with an offence who present with a significant mental health concern (e.g., mood, anxiety, and developmental disorders, schizophrenia) or substance use problem (Ontario Court of Justice [OCJ] 2011). The court's goals are to improve access to community treatment services, reduce case processing time, improve general well being, reduce the likelihood of re-offence, and increase community safety.

A process evaluation is distinct from an outcomes evaluation and specifically looks at program implementation and how a program facilitates change (Rossi and Freeman 1993). Process evaluations are important to conduct before outcomes can be assessed in order to understand the program is actually doing to achieve change (Steadman 2005). The objectives of the overarching evaluation were to 1) understand and represent the court's program theory, 2) explore program model implementation within the context of the YCJA, 3) describe how the court operates (with a particular focus on whether it is servicing its intended population), 4) examine what factors predict successful court completion, and 5) examine how the court addresses the mental health and criminogenic needs of its clients. The last three objectives are the focus of the current paper; the first two objectives are examined in a complementary paper (Davis Peterson-Badali and Skilling, 2014).

Study Objectives. For a comprehensive and systematic mental health court evaluation, Steadman (2005: 3) recommends collecting data on services received and participant characteristics to help answer the key question "what works, for whom, and under what circumstances?" Accordingly, the first set of objectives aimed to describe the operations of the 
court, including basic court processes, case processing, and treatment services accessed by youth. The second set of objectives focused on describing the youth seen in the court, including participant characteristics, differences in the characteristics of youth who completed the program and those who did not, and sample characteristics that predict successful completion of the program. Finally, a critical facet of the youth mental health court that requires exploration from a process perspective is how the court addresses both the mental health and criminogenic needs of youth. We examined the extent to which youths' treatment referrals matched their identified mental health needs, as well as the broad areas of criminogenic need identified in the literature (Hoge and Andrews 2002).

\section{Method}

\section{Participants}

Youth between the ages of 12 and 18, who had suspected mental health needs and wished to resolve their charges were eligible to participate in the mental health court (having a formal diagnosis was not a criterion). Youth excluded from the court included those who did not have mental needs or wished to contest their charges. A total of 184 young people participated in the mental health court from its inception in June 2011 until August 2013. Of those, information was collected on 127 youth (90 males and 37 females), representing all youths who participated meaningfully in the court (i.e., were engaged with the court long enough for a client file to be formally opened). Youths not included in the study had either not completed their court requirements at the time that data collection ceased $(n=27)$ or had not participated substantially in the program and, thus, a file was not opened (e.g., a young person was placed in the court but transferred out before a file could be opened, $n=15)$. The average age of participants was 16.35 
$(S D=1.78)$. Further details regarding participant characteristics are reported in the results section.

\section{Materials}

Government database. Information regarding participants' prior offences (date and type) was obtained through a government database that collects information on the criminal charges, findings (convictions), and dispositions of young people who receive a formal sanction through the criminal justice system.

Court files. Information gathered from court files included details of court operations (i.e., number of court dates, staff/personnel resources), as well as information pertaining to participants' charges and case processing time (i.e., number and type of court appearances, dates of court appearances, and dispositions).

Client files. Information regarding participant characteristics was gathered from client files compiled by the youth mental health court worker ${ }^{2}$. Client files consist of: 1) a program intake form including data collected directly from parents and youth;2) case notes written by the youth mental health court worker documenting significant client contact; and 3) written correspondence from treatment providers.

A data collection form was developed for the current study to standardize the information gathered from files in six key areas: 1) demographics; 2) court processing (e.g., parent involvement, referral information, contact dates, number of appearances, criminal charges); 3) mental health functioning (e.g., previous diagnoses, mental health screening scores); 4) treatment motivation; 5) treatment referral; and 6) program completion (i.e., date completed, court decision, degree of program completion). Treatment motivation was rated by the mental health court worker at the beginning and end of service on an11-point Likert scale that ranged from 0 
(completely unmotivated) to 10 (completely motivated). Information considered in the evaluation of treatment motivation included the youth mental health court workers interactions with the youth, the youths level of participation in treatment planning and treatment attendance, and information regarding treatment engagement provided by treatment providers. Treatment motivation was conceptualized following Ward Day Howells and Bigden's (2004) definition of motivation and readiness, with a particular focus on internal aspects of motivation including a desire to enter treatment and change behaviour, enthusiasm for treatment, a will to change, and belief that treatment will be meaningful. The data collection form also included a rating of the young person's degree of treatment and overall court completion: completed all (i.e., attended all treatment appointments or fulfilled assessment requirements), most (i.e., attended the majority of their treatment requirements or assessment sessions), some (i.e., attended only a few sessions or partially participated in an assessment), or none of the requirements (i.e., did not attend treatment).

The youth mental health court worker also collected data on participant mental health needs upon program entrance using the Massachusetts Youth Screening Instrument-Second Version (MAYSI-2, Grisso and Barnum 2001). The MAYSI-2 is a youth self-report measure designed to screen for signs of mental or emotional disturbance among youth aged 12-17 involved with the criminal justice system. The measure consists of 52 items to which youth indicate the presence or absence of various symptoms on seven subscales: alcohol/drug use, angry-irritable, depressed-anxious, somatic complaints, suicide ideation, thought disturbance and traumatic experience. Youth are categorized into the non-clinical range, the "caution" range (scored higher than two-thirds of justice-involved youth), or the "warning range" (scored in the top 5-15\% of justice-involved youth; Grisso and Barnum 2001). Overall, the MAYSI-2 is 
considered a reliable and valid screening measure (Archer Simonds-Bisbee Spiegel Handel and Elkins 2010). The test manual reports adequate to strong internal consistency $(r=.61-.86)$ for all subscales except the traumatic experiences subscale ( $r=.51$; Grisso and Barnum 2001). Testretest reliability coefficients range from .53 to .89 (Grisso and Barnum 2001). Concurrent validity, described as adequate (Grisso Barnum Fletcher Cauffman and Peuschold 2001), was established through correlations between MAYSI-2 scores and scores on the Millon Adolescent Clinical Inventory (MACI: Millon 1993) and the Youth Self Report (YSR; Achenbach 1991).

\section{Procedure}

A member of the research team reviewed court files and dockets and entered deidentified information into a secure electronic database. Client files were reviewed by the youth mental health court worker who then completed the data collection form. De-identified data from the forms were entered into a secure electronic database and hard copies of the form were transferred to secure storage.

\section{Results}

\section{Description of Court Operations}

Staff. The youth mental health court sat, on average, twice a month and was consistently staffed by a judge, a crown attorney, a youth mental health court worker, duty counsel, and administrative staff (i.e., a court reporter and courtroom clerk). A single judge staffed a significant proportion of court dates $(39.22 \%, n=20)$, with the remaining days being staffed from a pool of five judges. The crown, youth mental health court worker, and duty counsel roles were specifically dedicated to the mental health court and only changed when there was a change in personnel. Administrative staff varied but were selected from a core set of administrative staff 
at the courthouse. Youth who were not represented by duty counsel were represented by defence lawyers they retained (and paid for through legal aid or privately).

Referrals. Youths were referred to the mental health court through a variety of sources including duty counsel $(41.60 \%, n=52)$, defence lawyers $(26.40 \%, n=33)$, crown attorneys $(15.20 \%, n=19)$, bail program $(5.60 \%, n=7)$, probation officers $(4.80 \%, n=6)$, judges $(2.40 \%$, $n=3$ ), and others (e.g., doctors or other court workers; $4.00 \%, n=5$ ). Referrals were typically made when the referring agent was made aware of a young person's pre-existing mental health problems, when mental health problems were suspected, or when mental health problems were thought to be a contributing factor in the criminal charges. Prior to being transferred to the mental health court, cases appeared in the traditional youth court an average 5.14 times $(S D=$ $3.44, n=209)$, which took 78.47 days on average $(S D=80.30, n=209)$. Despite the time it took to be transferred in, once youths were referred it took just over a week ( $M=9.04$ days, $S D=$ $20.46, n=110$ ) for them to be seen by the youth mental health court worker.

Upon referral, the youth mental health court worker conducted a screening involving a standard intake form and a brief assessment of mental health needs using the MAYSI-2. Based on screening results, the youth mental health court worker made a recommendation regarding the young person's suitability for the program, as indicated by the presence of significant mental health or substance use concerns that contributed to, or were a complicating factor in, the young person's charges (OCJ 2011). Following screening, cases were referred to the crown attorney who further reviewed the case to determine eligibility (i.e., whether there was evidence of mental health needs and/or that mental health needs were an implicating factor in the case) and decided whether the youth was suitable for diversion or sentencing based on the seriousness of the offence, the youth's degree of participation, victim impact, and the proposed treatment plan. 
According to the program design, once a young person had completed intake and was accepted into the program, he or she was to be assigned a court date (OCJ 2011). In practice, almost a quarter of youths $(22.52 \%, n=25)$ had their court date on or before an intake appointment, indicating that they were not formally screened prior to court contact. It took, on average, almost a month (28.97 days) between date of referral and first court appearance $(S D=$ 25.27, $n=109$ ). Based on screening results, the youth mental health court worker developed a treatment plan that linked the young person with services in the community. Treatment plans designed to address mental health needs as well as the need for community safety and to hold the youth accountable - were devised following program acceptance to expedite the court process and quickly link the young person with treatment. It took, on average, approximately one month to connect youths requiring a new referral with a treatment provider $(M=1.07$ months, $S D=1.67$ months, $n=47$ ).

Treatment services. In terms of treatment services, 49 agencies received referrals for or provided services to young people. Youths were referred to an average of 1.48 unique treatment services $(S D=0.58, n=118)$ and attended an average of 1.29 different services $(S D=0.64, n=$ 103). Approximately half $(49.69 \%, n=79)$ of treatment referrals were made by the youth mental health court worker during the court process and were therefore a direct result of the young person's involvement in the court; the remaining $50.31 \%(n=80)$ referrals were to agencies to which young people were already connected and for which treatment had begun prior to their court involvement. The types and frequency of referrals are outlined in Table 1.

[Table 1 about here]

Case monitoring. As youths progressed through treatment, the youth mental health court worker monitored the case and provided regular updates to the crown attorney and legal counsel. 
During this process, youths were scheduled to return to court at various points for case monitoring. The average number of court appearances for those who completed their court requirements was $3.43(S D=2.21, n=102)$. Once youths had completed treatment or made significant progress, the crown attorney reviewed the case to determine an appropriate disposition. On average, youths were in treatment for 3.10 months ( $S D=2.00$ months, $n=49$ ) prior to their final court appearance. Where young people made significant progress, the crown considered a more favourable outcome in keeping with the severity of the charge (e.g., withdrawing or staying the charge). Youths who did not make significant progress were still eligible to have their cases dealt with through the mental health court but received a less favourable outcome (e.g., a probation disposition). Specifically, 85.58\% $(n=89)$ of youth had their charges withdrawn, while $2.88 \%$ received a discharge $(n=3), 2.88 \%(n=3)$ had their charges stayed, and $8.65 \%(n=9)$ were sentenced to probation. According to the youth mental health court worker's ratings of treatment program completion, $78.85 \%(n=82)$ of youths completed all or most program requirements, $20.19 \%(n=21)$ completed some program requirements, and $0.96 \%(n=1)$ did not complete any treatment requirements.

Case processing. The average length of case processing from first court date (regardless of court stream) to disposition in the mental health court was 168.18 days $(S D=102.90, n=171)$. Excluding time spent prior to entry into the mental health court, the average time from first youth mental health court date until completion was 90.47 days $(S D=68.48, n=171)$.

Non-Completion. For youth who did not complete their mental health court requirements, the most common reason was unwillingness to participate in, or comply with, treatment $(65.22 \% n=15)$. The remaining cases were transferred back into the traditional stream either because the youth mental health court worker recommended that participants were 
unsuitable for the mental health court $(13.04 \%, n=3)$, the youth's lawyer directed his or her client away from the court $(13.04 \%, n=3)$, or the youth was transferred to another courthouse $(8.70 \%, n=2)$. For cases that were transferred out of the mental health court, the average number of appearances prior to transfer was $1.88(S D=1.31, n=52)$, which took an average of 40.60 days $(S D=52.75, n=52)$ until the next court appearance.

\section{Participant Characteristics and Predictors of Program Completion}

Sample characteristics. Characteristics of participants, divided into 'completers' (i.e., completed court requirements, $81.89 \%, n=104$ ) and 'non-completers' (i.e., did not complete court requirements, $18.11 \%, n=23$ ), are reported in Table 2. Approximately a third of the sample was identified as experiencing one or more significant life stressors, including lack of parent involvement in court proceedings, involvement with child welfare agencies, school disengagement, and unstable housing. Group differences between completers and noncompleters on each characteristic were calculated using t-tests, chi-squared tests, or nonparametric tests (where non-normal data was a concern). Youths who completed the program were more likely to have at least one diagnosis $\left(\chi^{2}(2, \mathrm{~N}=113)=6.68, \mathrm{p}=.035\right)$ and were rated as having higher motivation at the beginning $(U(113)=541.50, \mathrm{Z}=-2.83, p=.005)$ and end $(U(110)=53.50, \mathrm{Z}=-2.84, p<.001)$ of treatment.

[Table 2 about here]

Charges. Information regarding participants' current and past charges were collected. Charges were categorized based on severity (e.g., from most to least violent), with similar charges grouped together under a single heading (e.g., various drug charges were categorized as “drug related charges"). In terms of criminal history, $37.20 \%(n=45)$ of the sample $(n=121)$ had previous charges, while $62.8 \%$ did not $(n=76)$. The average number of previous charges 
was $4.28(n=121, S D=12.12)$. With regards to current charges, youth had an average of four charges (see Table 2) associated with their court involvement (ranging from 1 to 17). When coded for most serious offence, the most common current charge was for assault $(40.16 \%, n=$ 51), followed by break and enter/theft/auto theft $(16.54 \%, n=21)$, drug possession/trafficking $(14.96 \%, n=19)$, and threatening $(7.87 \%, n=10)$. Violent charges related to sexual assault were rare $(2.36 \% n=3)$, as were robbery $(3.15 \%, n=4)$, possession of a weapon $(4.72 \% n=6)$, failure to comply/attend court $(5.51 \%, n=7)$, and miscellaneous charges $(4.72 \%, n=6)$. When looking at total charges (not the most serious), the most common were for those related to the administration of justice (i.e., failure to comply; $25.84 \%, n=130)$, common assault $(17.10 \%, n=$ 86), and break and enter/theft/auto theft $(11.33 \%, n=57)$.

The relationship between criminal charges and mental health needs was examined in a subset of 68 youth whose cases were ongoing at the time of data analysis. ${ }^{3}$ Charges were coded as directly, indirectly, or not at all related to youths' mental health functioning. A direct relationship, found in $20.59 \%$ of youth $(n=14)$, was coded when charges were incurred during a state of mental health distress (e.g., the youth committed an offence during a psychotic episode) or to support ongoing mental health problems (e.g., a youth with a substance use issue was caught with an illegal substance). An indirect relationship, found in $69.12 \%$ of youth $(n=47)$, was coded when other - non-mental health - factors (e.g., poor self-control, delinquent peer group, pro-criminal attitudes) were primarily associated with the offending behaviour but the youth was experiencing mental health difficulties that significantly impacted his or her ability to engage in treatment, or the mental health issue directly impacted criminogenic needs (e.g., a youth experienced social anxiety and as a result began to skip school and associate with 
delinquent peers, which led to him getting caught shoplifting). Finally, no relationship was found in $10.29 \%$ of youth $(n=7)$ who had no identified mental health needs.

Mental health functioning. Youths reported an average of 1.49 diagnoses during intake (see Table 2). Mood and anxiety disorders were the most common diagnosis, followed by attention deficit/hyperactivity disorder. Approximately $17.70 \%$ of participants reported no prior diagnoses and $6.45 \%(n=8)$ had no mental health needs (i.e., prior diagnoses or elevated scores on the MAYSI-2; see Table 3). With regards to the MAYSI-2, the most commonly identified elevation was on the somatic complaints subscale $(57.69 \%, n=60)$, followed by traumatic experience $(48.08 \%, n=50)$, angry-irritable $(45.19 \%, n=47)$, and depressed-anxious $(42.86 \%, n$ $=45) ; 32.69 \%(n=34)$ of participants had elevations with regards to suicidal ideation, $29.80 \%(n$ $=31$ ) of youth reported elevations on the alcohol/drug use subscale, and $36.98 \%$ of boys $(n=27)$ reported elevations on the thought disturbance scale. As noted above, completers were more likely to have at least one diagnosis, but there were no group differences in the average number of diagnoses or the likelihood of having at least one MAYSI-2 elevation (see Table 2).

[Table 3 about here]

Predictors of program completion. Two participant characteristics - having at least one diagnosis and motivation at beginning of treatment - were entered into a logistic regression model with court completion as the outcome. The model was significant $\left(\chi^{2}(2)=18.31 ; p=.000\right)$ and both diagnosis $\left(\chi^{2}(1)=6.11, p<.05\right)$ and motivation $\left(\chi^{2}(1)=11.27, p=.001\right)$ were significant predictors. For each one-point increase on the motivation scale youths were 1.65 times more likely to complete the court. The odds of completing the program were almost 5 times greater $\left(\mathrm{OR}=4.71, \mathrm{CI}_{95}=1.38-16.09\right)$ for youths with at least one diagnosis compared to those with none. 


\section{Extent to which mental health and criminogenic needs of participants were addressed}

In terms of the match ${ }^{2}$ between participants' treatment referrals and their mental health needs (identified based on previous diagnoses and/or MAYSI-2 elevations), half of participants $(50.85 \%, n=60)$ received treatment targeted towards identified needs (e.g., substance abuse treatment, first episode psychosis programs) or intensive enough to address multiple needs (e.g., hospital stays, psychiatric care, or residential treatment). Comprehensive assessments were sought for $11.02 \%(n=13)$ of youth. In contrast, referrals for generalized treatment not directed toward an explicitly identified need (e.g., general counselling, brief therapy) were made for $26.27 \%(n=31)$ of youth and treatment referral for needs not identified during screening were made for $11.86 \%(n=14)$ of youth.

Youths' treatment referrals were also coded for whether they addressed at least one of the eight domains of criminogenic need ${ }^{4}$. Participants were coded as receiving treatment for criminogenic needs (e.g., family counselling for family functioning difficulties; addictions services that addressed substance use needs) or receiving treatment for which it was unclear whether criminogenic needs were targeted (e.g., general counselling, individual counselling, brief therapy). Almost half of the sample $(48.31 \%, n=57)$ was referred for treatment that addressed at least one criminogenic need domain, while the remaining 51.69\% $(n=61)$ was not. Of youth who did not have criminogenic needs met, almost half $(47.46 \% n=28)$ received generalized mental health treatment (i.e., not targeted toward identified needs) and $6.78 \%(n=4)$ had treatment for needs not identified in their file. Just over one third $(35.60 \%, n=21)$ received either targeted or intensive treatment of their mental health needs and $10.17 \%(n=6)$ received assessments.

\section{Discussion}




\section{Operation of the Youth Mental Health Court}

Mental Health Screening and Treatment. Results indicate that mental health court referrals were typically initiated through legal professionals associated with the court (e.g., crown attorneys, lawyers, and judges). However, most legal professionals do not receive training in screening for mental health needs, highlighting the need for screening following referral. Despite its importance, almost a quarter of youth were seen in the court prior to being screened by the youth mental health court worker. Screening at the outset is imperative for determining suitability for the program and ensuring that youth without mental health needs are redirected into the traditional court stream.

With regards to treatment service referrals, youth were referred to, or received treatment from, almost 50 different programs that targeted a wide range of needs across a large geographic region. Difficulties with waitlists and treatment catchment areas may in part explain the need for such a wide range of services. It is important to consider the consistency and effectiveness of these treatment programs as they are integral to the outcomes of such courts (Boothroyd Mercado Poythress Christy and Petrila 2005). Given this vast array of services and the potential variability in treatment effectiveness, it may be particularly important for the current court to share treatment plans with service providers to ensure that youth are having their needs met.

Youth were in treatment for an average of approximately three months. There are several important factors that may be contributing to this relatively short treatment period. First, the court must ensure that youth do not spend additional time in the court for treatment purposes. While a youth may require intensive mental health services, proportionality considerations dictate that he or she not spend longer under the supervision of the court than a youth with comparable charges in a different court. Second, it is possible that many youth in the court have 
low severity of needs that require time-limited interventions. Third, it is possible that treatment services are not sufficiently intensive to meet youths' number and level of needs. There is some evidence to support this final hypothesis as our findings regarding treatment match revealed that only half of youth received treatment that appropriately targeted areas of mental health and criminogenic need. While it is important to continue to ensure that youth do not spend longer under the supervision of the court for their mental health needs, more could be done to develop treatment plans that properly guide the placement of youth in treatment services.

Case Processing Time. One of the goals of the youth mental health court was to reduce case processing to ensure timely access to treatment services for youth with mental health needs. This is also important given the concerns that have been raised regarding the potential for mental health court defendants to spend longer under the supervision of the court due to treatment than those who have been found guilty of similar offences in traditional court (Seltzer 2005). Based on data provided from the provincial government, the average time to disposition from April 2012 to March 2013 was 138 days in the traditional youth court system. At two other local courthouses the average times to disposition were 161 and 154 days. Calculated in the same manner, the average time to disposition for the mental health court cases (168) is in keeping with other courts. However, these findings do not allow for charge-related comparisons. It remains possible that youth spent more time in the mental health court for relatively minor offences than youth in the traditional system. Most mental health courts, including the one under evaluation, do not have written procedures regarding the length of supervision (Seltzer 2005). While flexibility in managing cases is ideal for addressing mental health needs, this can lead to an increase in court supervision. It may be important to have clearly articulated rules regarding case processing 


\section{TSpace Research Repository}

time to ensure that defendants do not spend longer in the mental health court than they would in the traditional court.

A closer look at case processing revealed that, once transferred into the court, cases were typically dealt with in a timely fashion, finishing on average in approximately 90 days. Thus, part of the challenge in reducing case processing stems from the time it takes for youths to be transferred into the mental health court (nearly 80 days). Discussion of wait times touches on wider systems issues with recognizing mental health needs earlier in the court process. Case processing could be improved by providing additional training opportunities for judges, defence counsel, and crowns to identify mental health issues, as well as building greater awareness of the existence of the youth mental health court. Researchers have also endorsed the use of mental health screening for all youth who come into contact with the court system (Grisso and Underwood 2004; Skowyra and Cocozza 2007). While this may be considered an unnecessary infringement on one's privacy, Grisso (2005) has argued that (aside from potential benefits associated with proper assessment and treatment of mental health issues) such screening is important to protect due process rights (e.g., fitness to stand trial). Systematic screening ensures these issues are considered up front to protect youth and ensure fairness in criminal proceedings. Another factor that may impact wait times is the one month lag to first court appearance for youth referred to the court. The court currently sits twice a month and may need to consider adding another date to accommodate new referrals. Finally, issues with regards to treatment waitlists and finding appropriate program referrals may be responsible for the one-month delay in connecting youth with treatment. This is particularly concerning as youth with mental health needs awaiting treatment have been found to be at increased risk for early recidivism compared to youth who completed treatment (Cuellar McReynolds and Wasserman 2006). 


\section{Characteristics of Youth Seen in the Mental Health Court}

Legal. With regards to total charges associated with the mental health court, the most common were related to the administration of justice, assault, and break and enter/theft/auto theft. These findings are generally in keeping with the pattern of most common youth court charges across Canada in 2011/2012 (i.e., theft, common assault, break and enter, and failure to comply; Dauvergne 2013). Over $90 \%$ of youth in the mental health court received dispositions in which their charges were stayed, withdrawn, dismissed or discharged compared to just over $40 \%$ of such dispositions in the general youth court population (Dauvergne 2013). Together, these results suggest that, in terms of charges, the court sees similar cases to those in the youth system as a whole, but diverts more youth - which is consistent with the court's mandate.

Mental Health Needs. A broad range of mental health needs was identified amongst participants, with the most common related to mood and anxiety disorders. In addition, approximately half of youth reported elevations on the MAYSI-2 in traumatic experiences, somatic complaints, and angry-irritable symptoms. The high proportion of youth with at least one diagnosis $(82 \%)$ is consistent with past findings of justice-involved youth across North America (Drerup Croysdale and Hoffman 2008; Gretton and Clift 2011; Unruh Gau and Waintrup 2009; Vieira et al. 2009; Wasserman McReynolds Schwalbe Keating and Jones 2010) and suggests the need for comprehensive assessments and services that are trauma informed and address each youth's unique needs.

Importantly, more than 1 in 20 youth processed through the mental health court had no previous diagnoses and no elevations on the MAYSI-2. This is particularly concerning as the purpose of mental health courts is to assist those with mental health needs access treatment and improve mental health functioning. Allowing youth without mental health needs to access the 


\section{TSpace Research Repository}

court is incompatible with purpose of such courts, misdirects scarce mental health resources, and may detract from the court's ability to show positive outcomes. There is no evidence that the court purposefully targets youth without mental health needs. Possible reasons that youth without mental health needs were accepted into the court include the court's lack of clear inclusion and exclusion criteria for program acceptance and failure to consistently follow the prescribed referral process. Having clearly identified eligibility criteria is considered one of the key factors for a successful mental health court program (Thompson Osher, and Tomasini-Joshi 2012)

These findings take on greater significance in light of the fact that not having a diagnosis was significantly more common amongst 'non-completers' than those who completed their involvement in the youth mental health court. Youth without mental health needs may not be as motivated or engaged as those who had clear difficulties that could be addressed in treatment. Indeed, $40 \%(n=8)$ of those without a diagnosis did not finish their court requirements; of those, two were screened out but the remaining six were transferred due to lack of desire to engage in treatment. In addition, treatment motivation at the beginning of service significantly predicted program completion. These findings suggest that treatment motivation and the presence of mental health difficulties should be properly screened during intake and considered during treatment planning. It may be important to include a motivational enhancement component to treatment for youth who express low motivation to improve program completion rates. It is important to note, that while youth without mental health needs made up a portion of the noncompleters, there were a number of youth with mental health needs who did not complete their program requirements. While some may have been transferred for legal reasons, it is important to consider the possibility that many of these youth may have been unmotivated to participate in treatment due to stigma and/or a lack of match between needs and treatment. 
Additional Vulnerabilities. In addition to mental health needs, a significant subgroup of participants lacked some of the key supports essential for healthy development. Approximately one third of youth did not have parental support in managing their court requirements, had involvement with the child welfare system, and/or were not living with family. The importance of parental involvement in the youth justice system has been highlighted within the YCJA (2002) and best practice guidelines for rehabilitating justice-involved youth (Guerra Kim and Boxer 2008). Without parental support, youth may experience increased stress and struggle to adhere to court requirements. Family functioning difficulties are also a key predictor of recidivism and, thus, engaging this support system may be essential for rehabilitation. Similarly, research has highlighted the added difficulties youth experience when navigating multiple systems (e.g., the child welfare and justice systems; Herz Ryan and Bilchick 2010). Those in shelters or with unstable residences are at particular risk for future mental health and criminal involvement (Cauce Paradise Ginzler Embry Morgan Lohr and Theofelis 2000). Overall, these findings are also consistent with research noting the general lack of parent involvement in youth court proceedings (Peterson-Badali and Broeking 2010) and family functioning difficulties found amongst justice-involved youth (Ulzen and Hamilton 1998; Vieira Skilling and Peterson-Badali 2009; Vitopoulos Peterson-Badali and Skilling 2012).

In addition, almost a third of youths were not involved in school at the time of referral. Educational underachievement and truancy have both been linked to criminal behaviour in young people and are a risk factor for recidivism (Cottle Lee and Heilbrun 2001; Maguin and Loeber 1996; Simons Whitbeck Conger and Conger 1991). In contrast, engagement in school and educational achievement have been identified as important protective factors in high risk youths and may be important to consider in intervention (Catalano and Hawkins 1996; Davis et al. 2014; 
Hoge Andrews and Leschied 1996). These findings are consistent with past research documenting the high level of educational need in justice-involved youth (Chitsabesan Kroll Bailey Kenning Sneider MacDonald and Theodosiou 2006; Vieira et al. 2009). Together, these results highlight the challenges and potential risk factors that young people involved with the mental health court face on daily basis. There is no doubt that these stressors, above and beyond mental health needs, impinge on a young person's ability to navigate the legal system and engage in treatment. Because both family functioning and educational difficulties are known risk factors for recidivism (Hoge and Andrews 2002), a proper assessment of these areas may be important to ensure they are being addressed in treatment.

\section{Extent to which Youths' Needs Were Addressed through the Court Process}

Well over half of youths received intensive or targeted treatment or an in-depth assessment of their needs. In contrast, a quarter of youths were referred for treatment services that were unspecified, while $11 \%$ were referred for needs not identified in their file. The latter statistics are concerning as it is unclear the degree to which such treatments are targeting the most prevalent needs of youth. The degree to which treatment mapped onto the broad areas of criminogenic need was also assessed. In almost half of the cases, youth were not referred for treatment that clearly addressed areas of criminogenic need. Because reducing recidivism is one of the long-term stated goals of the program it is important to consider how the court can meet both the criminogenic and mental health needs of justice-involved youth.

Several factors may contribute to the divergence between needs and treatment. First, the court does not explicitly assess or address areas of criminogenic need. As highlighted earlier, criminogenic needs are important to address for those whose criminal behaviours are not directly related to their mental health functioning (Skeem et al. 2011). There was an indirect relationship 
between charges and mental health functioning for a majority of participants. For these youth it is particularly important for treatment to address criminogenic needs. Secondly, the MAYSI-2 may not be sufficient for conceptualizing young people's mental health needs, as it was developed as a screening device and not for formal diagnoses or long-range treatment planning (Grisso et al. 2001). Young people who score high on this measure may require further assessment. Thirdly, results of the intake and screening are not systematically shared with treatment providers, making it difficult for them to tailor treatment towards identified needs. Fourthly, treatment can only be as strong as that which is available in the community. Difficulties with waitlists and a lack of evidence-based practice within these services may result in treatment that is less than ideal.

Moving forward, the court would benefit from implementation of systematic in-depth assessment of criminogenic need, mental health, and motivation in order to address the varied needs of its clientele. Evidence-based practice in psychology has highlighted the importance of properly identifying client needs and designing treatment plans that consider each individual's unique profile (American Psychological Association 2006). It will also be important to systematically share assessment results with treatment services so they can tailor treatment to meet identified needs, as treatment that does not consider the client's unique profile is less likely to be effective (Mash and Hunsley 2005).

\section{Limitations and Future Research}

There are several important limitations to keep in mind with regards to the current study. First, due to variations in court models, operations, and populations, as well as the small sample size, the results of this study are not directly generalizable to other courthouses. Nevertheless, we provide important details on the functioning of the court that may be applied to other court 
models. Secondly, lack of resources (i.e., limited availability of court staff and limited time with youth) made it difficult to implement formalized and standardized measures that could have provided a more in-depth understanding of the court population. For instance, standardized measures of mental health functioning, criminogenic need, and treatment motivation could provide further insight into how to best meet the needs of this population. Future research should aim to introduce standardized measures, formalize data collection procedures, and assess the impact of the court on improving mental health functioning and reducing recidivism.

\section{Conclusion}

The youth mental health court under evaluation has made strong gains since its inception. The court provides services in a timely manner to youth with a broad array of mental health diagnoses. Case processing times within the court were generally found to be in keeping with traditional youth court programs. In addition to these areas of strength, there are several important areas for improvement. Our findings indicate that youth spent a significant amount of time in the traditional court before being transferred into the mental health court. In addition, a proportion of mental health court defendants were actually found to have no mental health needs whatsoever. This is particularly concerning as these youth are unlikely to benefit from treatment services. Part of the difficulty with both case processing time and accepting inappropriate participants is the lack of systematic screening within the court. Systematic screening with clear inclusion and exclusion criteria is essential to help identify potential candidates earlier in the court process and can redirect ineligible youth back into the traditional court system.

Perhaps one of the most important findings was that approximately half of youth did not receive treatment matched to their mental health needs and another half of youth did not have areas of criminogenic need addressed through treatment. The latter finding is particularly salient 
given that the large majority of the sample was found to have charges that were indirectly related to their mental health needs, suggesting that there are other areas of need that are more directly impacting offending behaviour. In keeping with the empirical evidence for treating justice involved youth with mental health needs, it will be important for the court to consider how it can address both the mental health and criminogenic needs of its clients. This will likely involve the screening and/or assessment of both areas of need that can then inform targeted treatment plans and proper treatment placement. 
Table 1. Frequency of Youth Mental Health Court Treatment Referrals

\begin{tabular}{lcc}
\hline \multicolumn{1}{c}{ Referral } & $N$ \% of total referrals made \\
\hline Counselling & 56 & 32.00 \\
Intensive Mental Health Treatment & 39 & 22.28 \\
Substance Use & 28 & 16.00 \\
Assessments & 19 & 10.85 \\
Anger and Aggression & 11 & 6.28 \\
Social Support (i.e., family, community) & 8 & 4.57 \\
Educational & 7 & 4.00 \\
Developmental Disability & 1 & 0.58 \\
Other & 6 & 3.44 \\
Total & 175 & 100.0 \\
\hline
\end{tabular}


Table 2. Characteristics of Youth Mental Health Court Participants

\begin{tabular}{|c|c|c|c|c|c|c|}
\hline & \multicolumn{2}{|c|}{ Total Sample } & \multicolumn{2}{|c|}{ Completers } & \multicolumn{2}{|c|}{ Non-Completers } \\
\hline & Mean $(S D)$ & $N$ & Mean $(S D)$ & $N$ & Mean $(S D)$ & $N$ \\
\hline $\operatorname{Age}^{1}$ & $16.35(1.78)$ & 127 & $16.37(1.22)$ & 104 & $16.26(0.94)$ & 23 \\
\hline Grade & $10.75(0.97)$ & 79 & $10.73(0.98)$ & 67 & $10.83(0.94)$ & 12 \\
\hline Number of charges & $3.97(3.55)$ & 127 & $3.75(3.28)$ & 104 & $4.96(4.55)$ & 23 \\
\hline \# diagnoses (including ODD/CD) ${ }^{2}$ & $1.49(1.08)$ & 113 & $1.54(1.24)$ & 91 & $1.27(1.28)$ & 22 \\
\hline \# diagnoses (excluding ODD/CD) & $1.35(1.08)$ & 113 & $1.40(1.05)$ & 91 & $1.18(1.18)$ & 22 \\
\hline Initial Motivation & $5.48(1.95)$ & 115 & $5.75(1.75)$ & 96 & $4.11(2.38)$ & 19 \\
\hline & $\%(n)$ & $N$ & $\%(n)$ & $N$ & $\%(n)$ & $N$ \\
\hline Male & $70.86(90)$ & 127 & $69.23(72)$ & 104 & $78.26(18)$ & 23 \\
\hline Female & $29.13(37)$ & 127 & $30.77(32)$ & 104 & $21.74(5)$ & 23 \\
\hline Parent involvement at court & $63.93(78)$ & 122 & $63.64(63)$ & 99 & $65.22(15)$ & 23 \\
\hline Any child welfare involvement & $26.83(33)$ & 123 & $27.00(27)$ & 100 & $26.09(6)$ & 23 \\
\hline Currently residing with parents & $61.98(75)$ & 121 & $58.65(61)$ & 104 & $63.64(14)$ & 22 \\
\hline Currently in school & $70.25(85)$ & 121 & 73.74 (73) & 99 & $54.55(12)$ & 22 \\
\hline Currently employed & $14.75(18)$ & 122 & $16.00(16)$ & 100 & $9.10(2)$ & 22 \\
\hline Probation order & $18.52(20)$ & 108 & $16.85(15)$ & 89 & $26.32(5)$ & 19 \\
\hline At least one diagnosis & $82.30(93)$ & 113 & $86.81(79)$ & 91 & $63.64(14)$ & 22 \\
\hline Elevation on MAYSI-2 & $81.73(85)$ & 104 & $80.68(71)$ & 88 & 87.50 (14) & 16 \\
\hline
\end{tabular}

\footnotetext{
${ }^{1}$ Age was calculated based on time of referral or, when referral information was not available, first court date.

${ }^{2}$ Total number of diagnoses was calculated including and excluding diagnoses of Conduct Disorder (CD) and Oppositional Defiant Disorder (ODD), as these diagnoses highly overlap with the behaviours that result in criminal justice involvement.
} 


$\begin{array}{lllllll}\text { No mental health concerns } & 6.45(8) & 124 & 5.94(6) & 101 & 8.70(2) & 23\end{array}$

Table 3. Frequency of Prior Mental Health Diagnoses for Youth in the Mental Health Court All Youth Completers Non-Completers

\begin{tabular}{|c|c|c|c|}
\hline \multirow[b]{2}{*}{ Diagnoses } & \multirow{2}{*}{$\%(n)$} & \multirow{2}{*}{$\%(n)$} & \multirow{2}{*}{$\%(n)$} \\
\hline & & & \\
\hline Mood and Anxiety Disorders & $53.98(61)$ & $58.24(53)$ & $36.36(8)$ \\
\hline Autism Spectrum Disorders & $4.42(5)$ & $5.49(5)$ & -- \\
\hline Psychotic Disorders & $7.96(9)$ & $6.59(6)$ & $13.64(3)$ \\
\hline Substance Abuse Disorders & $8.85(10)$ & $8.79(8)$ & $9.10(2)$ \\
\hline Fetal Alcohol Spectrum Disorder & $9.73(11)$ & $9.90(9)$ & $9.10(2)$ \\
\hline Externalizing Disorders & $11.50(13)$ & $12.09(11)$ & $9.10(2)$ \\
\hline Attention Deficit/Hyperactivity Disorder & $28.32(32)$ & $27.47(25)$ & $31.81(7)$ \\
\hline Cognitive Disorders & $12.39(14)$ & $12.09(11)$ & $13.64(3)$ \\
\hline Other (e.g., attachment disorder) & $11.50(13)$ & $13.19(12)$ & $4.55(1)$ \\
\hline None & $17.70(20)$ & $13.19(12)$ & $36.36(8)$ \\
\hline
\end{tabular}




\section{References}

Achenbach, Thomas

1991 Manual for the Child Behavior Checklist. Burlington: University of Vermont Department of Psychiatry.

Archer, Robert P., Elise C. Simonds-Bisbee, David R. Spiegel, Richard W. Handel and David E. Elkins

2010 Validity of the Massachusetts Youth Screening Instrument-2 (MAYSI-2) Scales in Juvenile Justice Settings. Journal of Personality Assessment 92: 337-348.

American Psychological Association

2006 Evidence-Based Practice in Psychology. American Psychologist 61: 271-285.

Andrews, D. A. and James Bonta

2010 Rehabilitating Criminal Justice Policy and Practice. Psychology, Public Policy, and Law 16: 39-55.

Andrews, D. A., James Bonta and R. D. Hoge

1990 Classification for Effective Rehabilitation: Rediscovering Psychology. Criminal Justice and Behavior 17: 19-52.

Behnken, Monic P.

2008 An Evaluation of the Nation's First Juvenile Mental Health Court for Delinquent Youth with Chronic Mental Health Needs. Doctoral dissertation, Pacific Graduate School of Psychology

Bonta, James

1995 The Responsivity Principle and Offender Rehabilitation. Forum on Corrections Research 7. 
Boothroyd, Roger A., Cynthia Calkins Mercado, Norman G. Poythress, Annette Christy and John Petrila

2005 Clinical Outcomes of Defendants in Mental Health Court. Psychiatric Services 56: 829-834.

Boothroyd, Roger A., Norman G. Poythress, Annette McGaha and John Petrila

2003 The Broward Mental Health Court: Process, Outcomes and Service Utilization. International Journal of Law and Psychiatry 26: 55-71.

Callahan, Lisa, Joseph Cocozza, Henry J. Steadman and Sheila Tillman

2012 A National Survey of U.S. Juvenile Mental Health Courts. Psychiatric Services 63: $130-134$.

Catalano, Richard F., and J. David Hawkins

1996 The Social Development Model: A Theory of Antisocial Behavior. In J. David Hawkins (Ed.), Delinquency and crime: Current theories. New York: Cambridge University Press.

Cauce, Ana M., Matthew Paradise, Joshual A Ginzler, Lara Embry, Charles J. Morgan, Yvette Lohr and Jim Theofelis

2000 The Characteristics and Mental Health of Homeless Adolescents: Age and Gender Differences. Journal of Emotional and Behavioral Disorders 8: 230-239.

Chitsabesan, Prathiba, Leo Kroll, Sue Bailey, Cassandra Kenning, Stephanie Sneider, Wendy MacDonald and Louise Theodosiou

2006 Mental Health Needs of Young Offenders in Custody and in the Community. The British Journal of Psychiatry 188: 534-540.

Cottle, Cindy C., Ria J. Lee and Kirk Heilbrun 
2001 The Prediction of Criminal Recidivism in Juveniles. Criminal Justice and Behavior 28:367-394.

Cuellar, Allison E., Larkin S. McReynolds and Gail A. Wasserman

2006 A Cure for Crime: Can Mental Health Treatment Diversion Reduce Crime Among Youth? Journal of Policy Analysis and Management 25: 197-214.

Dauvergne, Mia

2013 Youth Court Statistics in Canada, 2011/2012. Juristat catalogue no. 85-002-X:

Davis, Krista, Michele Peterson-Badali and Tracey Skilling

2014 A Theoretical and Qualitative Evaluation of a Youth Mental Health Court Program Model. Submitted for Publication.

Drerup, Lauren C., Allison Croysdale and Norman G. Hoffman

2008 Patterns of Behavioral Health Conditions Among Adolescents in a Juvenile Justice System. Professional Psychology: Research and Practice 39: 122-128.

Gretton, Heater M. and Robert J. W. Clift

2011 The Mental Health Needs of Incarcerated Youth in British Columbia, Canada. International Journal of Law and Psychiatry 34: 109-115.

Grisso, Thomas

2005 Why we need Mental Health Screening and Assessment in Juvenile Justice Programs. In Thomas Grisso, Gina Vincent, and Daniel Seagrave (Eds.), Mental Health Screening in Juvenile Justice. New York: Guilford Press

Grisso, Thomas and Richard Barnum

2001 Massachusetts Youth Screening Instrument: Second version (MAYSI-2). Worcester: University of Massachusetts Medical School. 
Grisso, Thomas, Richard Barnum, Kenneth E. Fletcher, Elizabeth Cauffman and Dawn

Peuschold

2001 Massachusetts Youth Screening Instrument for Mental Health Needs of Juvenile Justice Youths. Journal of the American Academy of Child and Adolescent Psychiatry 40: 541-548.

Grisso, Thomas and Lee A. Underwood

2004 Screening and assessing mental health and substance use disorders among youth in the Juvenile Justice System: A Resource Guide for Practitioners. Delmar, NY: National Center for Mental Health and Juvenile Justice.

Guerra, Nancy G., Tia E. Kim and Paul Boxer

2008 What Works: Best Practices with Juvenile Offenders. In Robert D. Hoge, Nancy G. Guerra and Paul Boxer (Eds.), Treating the Juvenile Offender. New York: The Guilford Press.

Heretick, Donna M.L., and Joseph A. Russell.

2013 The Impact of Juvenile Mental Health Court on Recidivism Among Youth. OJJDP Journal of Juvenile Justice 3: 1-14.

Herz, Denice C., Joseph P. Ryan, and Shay Bilchick

2010 Challenges Facing Crossover Youth: An Examination of Juvenile-Justice Decision Making and Recidivism. Family Court Review 48: 305-321.

Hoge, R. D. and D. A. Andrews

2002 The Youth Level of Service/Case Management Inventory. Toronto, ON: MultiHealth Systems.

Hoge, R. D., D. A. Andrews and Alan W. Leschied 
1996 An Investigation of Risk and Protective Factors in a Sample of Youthful Offenders. Journal of Child Psychology and Psychiatry 37: 419-424.

Hollin, Clive. R., and Emma J. Palmer

2003 Level of Service Inventory-Revised Profiles of Violent and Nonviolent Prisoners. Journal of Interpersonal Violence 18: 1075-1086.

Maguin, Eugene and Rolf Loeber

1996 Academic Performance and Delinquency. Crime and Justice 20: 145-264.

Mash, Eric J. and John Hunsley

2005 Evidence-Based Assessment of Child and Adolescent Disorders: Issues and Challenges. Journal of Clinical Child and Adolescent Psychology 34: 362-379.

Millon, Theodore

1993 Millon Adolescent Clinical Inventory: Manual. Minneapolis: National Computer Systems.

Ontario Court of Justice

2011 The Community Youth Court: Description. Retrieved from http://www.hsjcc.on.ca/Uploads/Community\%20Youth\%20Court\%20 Description\%20-\%20May\%204\%202011.pdf

Perkins-Mcvey, H., Hillary McCormick, Johanne Leger, Tania Breton and Greg Motayne 2009 Ottawa Youth Mental Health Court: Finding Hope in a Court Room. Presentation at the Meeting of the Human Services and Justice Coordinating Committee, Niagara Falls, Ontario.

Peterson-Badali, Michele and Julia Broeking

2010 Parents' Involvement in the Youth Justice System: Rhetoric and Reality. 
Canadian Journal of Criminology and Criminal Justice 52: 1-27.

Rossi, Peter H. and Howard E. Freeman

1993 Evaluation: A Systematic Approach (5 ${ }^{\text {th }}$ ed.). Newbury Park, CA: Sage Publications.

Seltzer, Tammy

2005 Mental Health Courts: A Misguided Attempt to Address the Criminal Justice System's Unfair Treatment of People with Mental Illnesses. Psychology, Public Policy, and Law 11: 570-586.

Sarteschi, Chistine M., Michael G. Vaughn and Kevin Kim

2011 Assessing the Effectiveness of Mental Health Courts: A Quantitative Review. Journal of Criminal Justice 39: 12-20.

Schlager, Melinda D., and Daniel Pacheco

2011 LSI-R Scores Over Time: Making the Case for Needs-Based Case Management. Criminal Justice and Behavior 38: 541-553.

Schneider, Richard D., Hy Bloom and Mark Hereema

2007 Mental health courts: Decriminalizing the mentally ill. Toronto: Irwin Law.

Simons, Ronald L., Les B. Whitbeck, Rand D. Conger and Katherine J. Conger

1991 Parenting Factors, Social Skills, and Value Commitments as Precursors to School Failure, Involvement with Deviant Peers, and Delinquent Behavior. Journal of Youth and Adolescence 30: 645-664.

Simourd, David J.

2004 Use of Dynamic Risk/Needs Assessment Instruments Among Long-term Incarcerated Offenders. Criminal Justice and Behavior 31: 306-323.

Skeem, J.ennifer L., Sarah Manchak, and Jillian K. Peterson 
2011 Correctional Policy for Offenders with Mental Illness: Creating a New Paradigm for Recidivism Reduction. Law and Human Behavior 35: 110-126.

Skowyra, Kathleen R. and Joseph J. Cocozza

2007 Blueprint for Change: A Comprehensive Model for the Identification and Treatment of Youth with Mental Health Needs in Contact with the Juvenile Justice System. Delmar, NY: The National Center for Mental Health and Juvenile Justice.

Slinger, Emily, and Ronald Roesch

2010 Problem-Solving Courts in Canada: A Review and a Call for Empirically-Based Evaluation Methods. International Journal of Law and Psychiatry 33: 258-264.

Steadman, Henry J.

2005 A guide to collecting mental health court outcome data. New York: Council of State Governments.

Steadman, Henry J., Allison Redlich, Lisa Callahan, Pamela C. Robbins and Roumen Vesselinov

2011 Effect of Mental Health Courts on Arrests and Jail Days: A Multisite Study. Archives of General Psychiatry 68: 167-172.

Thompson, Michael, Fred Osher and Denise Tomasini-Joshi

2007 Improving responses to people with mental illnesses: The essential elements of a mental health court. New York: Council of State Governments Justice Center.

Ulzen, Thaddeus P. M., and Hayley Hamilton

1998 The Nature and Characteristics of Psychiatric Comorbidity in Incarcerated Adolescents. Canadian Journal of Psychiatry 43: 57-63.

Unruh, Deanne K., Jeff M. Gau and Miriam G. Waintrup 2009 An Exploration of Factors Reducing Recidivism Rates of Formerly Incarcerated 
Youth with Disabilities Participating in a Re-entry Intervention. Journal of Child and Family Studies 18: 284-293.

Vieira, Tracey A., Tracey A. Skilling and Michele Peterson-Badali

2009 Matching Court Ordered Services with Treatment Needs: Predicting Treatment Success with Young Offenders. Criminal Justice and Behavior 36: 385-401.

Vitopoulos, Nina A., Michele Peterson-Badali and Tracey A. Skilling

2012 The Relationship Between Matching Service to Criminogenic Need and Recidivism in Male and Female Youth: Examining the RNR Principles in Practice. Criminal Justice and Behavior 39: 1025-1041.

Ward, Tony, Andrew Day, Kevin Howells and Astrid Birgden

2004 The Multifactor Offender Readiness Model. Aggression and Violent Behavior 9: 645-673.

Wasserman Gail A., Larkin S. McReynolds, Craig S. Schwalbe, Joseph M. Keating and Shane A. Jones

2010 Psychiatric Disorder, Comorbidity, and Suicidal behavior in Juvenile Justice Youth. Criminal Justice and Behavior 37: 1361-1376.

\section{Legislation Cited}

Youth Criminal Justice Act, S.C. 2002, c. 1. 


\section{End Notes}

${ }^{1}$ The clearest exception to this is Substance Use Disorder, a diagnosis which has also been established in research as a criminogenic need.

${ }^{2}$ The youth mental health court worker is a mental health specialist (i.e., typically an individual with a graduate degree in a related field) who plays an integral role in the court (e.g., screening youth, conducting intake assessments, developing treatment plans, making treatment referrals, liaising with treatment agencies, monitoring the youth's progress, and liaising with the crown attorneys and defense lawyers).

${ }^{3}$ It was not possible to reliably code cases that had closed prior to the study, as sufficient information was not available in participants' files.

${ }^{4}$ Two independent judges coded a random subset of 26 files; kappa values (1.0) revealed 100\% agreement for coding of match between treatment provided and youths' identified mental health needs and criminogenic needs. 